\title{
The Numerical Simulation Study of the Impacting Factors of the Produced Gas/Oil Ratio
}

Zhenhai Jiang

No.3 Oil Production Factory, Daqing Oil Field Limited Company, Daqing City, Heilongjiang Province, 163000

\begin{abstract}
In the conditions of pressure maintenance when balanced injection and production rate, produced gas-oil ratio should remain stationary. Conversely, take Sabei oilfield as an example, along with the development entered high water cut period, the value of its produced gas-oil ratio increased significantly. In view of this abnormal phenomenon, firstly, we analyze the impacting factors of the produced gas/oil ratio theoretically. It include well spacing density, bottom hole flowing pressure and saturation pressure. In terms of those impacting factors, we carry out the study through numerical simulation. As the results indicated, the produced gas/oil rises with the increase of the well spacing density and saturation pressure, increasing with the decrease of the bottom hole flowing. Additionally, the effect of those factors is not obvious when the water is low in earlier days, the produced gas/oil ratio sudden increase with the water cut rises.
\end{abstract}

\section{Preface}

There are numerous investigations of the chemical composition of hydrocarbons in reservoir, the property of multi-component and liquid state mixture, the features and conditions of phase transformation, which have yielded a complete theoretical system of phase state of the hydrocarbons. The common method to describe (compare and predict) the volume changes of the composed system of hydrocarbons is the produced gas/oil ratio during the process of production ${ }^{[1]}$.

The main researching object of laboratoryexperiments is condensate oil/gas reservoir, which have been demonstrated that the weight of gas in it is higher than oil and it is hard to identify the selected layer of it, we have measured the physical property parameter of fluids of various gas/oil ratios, and have conducted the physical experiment of fluid-saturated rock to do surveying investigations at the simulated reservoir environment. The result of this experiment indicates that with the change of gas phase ,the velocity of sound, coefficient of volume compressibility are the most easily to change, the hydrogen index could change a lot, there are micro density difference between the light oil of high gas/oil ratio and the condensate gas of low gas/oil ratio. With the increasing of gas/oil ratios of injected fluid, the velocity of longitudinal wave, bulk modulus, the velocity ratio of the longitudinal and transverse wave are decreasing, the velocity of transverse wave is increasing a little. The result of this experiment could help providing foundation for constructing the model to identify the condensate oil/gas reservoir by well logging ${ }^{[1]}$.

For example, in Daqing Oilfield, the researcher utilized the following data to investigate the producing gas/oil ratio, they are chemical composition monitoring data of oil and gas of different water content period, pressure cord data, the producing gas/oil ratio data in a well at a layer and the result of the numerical simulation of producing gas/oil ratio at the condition of water flooding, they investigated and concluded the change law of producing gas/oil ratio in La, Sa, Xing oilfield using a systematical theory means, and then took it into the real production to demonstrate it, came out a conclusion that there is no essential relation between water content and producing gas/oil ratio; Pressure is a vital factor in the change of gas/oil ratio, the producing gas/oil ratio is consistent with original gas/oil ratio in the condition of keeping up the pressure by water injection, while there is no necessary relation between the value of the pressure differential between well-flowing and the saturation pressure and the producing gas/oil ratio ${ }^{[2]}$.

The investigations of producing gas/oil ratio of the gas cap oilfield named as Lamadian is based on system engineering theory and the dissipative structure theory, the researcher investigated the change characteristics of producing gas/oil ratio of Lamadian oilfield by material balance method, geophysical well logging method, hydrocarbon detection method and producing gas/oil ratio detection etc, the result indicated that the reason which leading to the increasing of producing gas/oil ratio as following, the imbalanced pressure in local regions lead to the gas channeling of the connected gas cap ${ }^{[3]}$.

The investigation of producing gas/oil ratio of condensate gas reservoir indicates that, when the condensate gas reservoir at the driving type of depletion, the condensate gas of the reservoir is in the phase of single gas after the time of the pressure is higher than the dew point pressure, the value of producing gas/oil ratio should be a constant; while the pressure is lower than the dew point pressure, the liquid will retrograde fall out, and then the producing gas/oil ratio will increase. The gas/oil ratio of Yu-futsu condensate field in Japanese, the Yakala condensate gas reservoir and the Dalaoba condensate gas reservoir in China is abnormal, with the pressure releasing, the producing gas/oil ratio of most of gas well doesn't rise, some part of these gas well will sharply decline. Research results show that, the main reason that lead to producing gas/oil ratio declining are water invasion, compositional gradient, compositional abnormity, reservoir property and capillary number effect $^{[4]}$.

There was changing law investigations of producing gas/oil ratio in Tazhong I gas field, we concluded the changing rule of gas/oil ratio in the eastern test area of Tazhong I gas field, by the comprehensive application of the data of core testing, well logging, geophysical prospecting, well testing and production testing, the analysis show that there are four changing types of the 
gas/oil ratio when the well is producing: no obvious changing type, ascending slowly type, constant descending type, descending after ascending type. The main reasons which lead to the changed gas/oil ratio are the change of pressure and temperature, the different fluid property, the retrograde condensation. The well whose gas/oil ratio is no obvious changing, its' major are apparent homogeneity, the well whose gas/oil ratio descend constantly, its' reservoir type is fracture, the well whose gas/oil ratio is descending after ascending, its' reservoir type maybe the double porosity media ${ }^{[5]}$.

After surveyed amount of documents, we came out a result manifest that, the most of abnormal activity researching of producing gas/oil ratio are focusing on condensate gas reservoir and gas field, besides, the researcher have investigated massive dissolved gas/oil ratio problems when its' driving power is dissolved gas, but the change law investigations of producing gas/oil ratio at the condition of water flooding are very few. This paper use the Sabei oilfield as a example, we established a theoretical formula of well spacing density, flowing bottom hole pressure, saturation pressure and producing gas/oil ratio, after that, we analyzed the change law of producing gas/oil ratio caused by the well spacing density, flowing bottom hole pressure, saturation pressure by the means of numerical simulation ${ }^{[6]}$.

\section{Theoretical analysis}

According to the flow pattern, the vadose region can be divided into two flow regimes (Figure 2-1), in gassed out regimes, all of the oil, gas, water phases should be taken into consideration, while in non degassing regimes, only oil and water phases should be taken into consideration, these two flow regimes obey different vadose law.

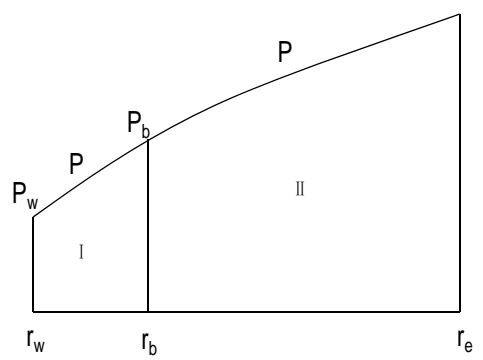

Figure 2-1 Formation pressure distribution after oil well degassing

According to the pressure distribution of oil, gas, water phases in gassed out regimes, the calculation formula of radius of gassed out regimes ${ }^{[7]}$ as follows:

$$
\ln r_{b}=\frac{\left[p_{b}-p_{w f}-c\left(p_{b}-p_{w f}\right)^{2}\right] \ln r_{e}+\left(p_{e}-p_{b}\right) \ln r_{w}}{\left[p_{b}-p_{w f}-c\left(p_{b}-p_{w f}\right)^{2}\right]+\left(p_{e}-p_{b}\right)}
$$

Owing to

$$
r_{e}=d / 2
$$

$$
\ln r_{b}=\frac{\left[p_{b}-p_{w f}-c\left(p_{b}-p_{w f}\right)^{2}\right] \ln \frac{d}{2}+\left(p_{e}-p_{b}\right) \ln r_{w}}{\left[p_{b}-p_{w f}-c\left(p_{b}-p_{w f}\right)^{2}\right]+\left(p_{e}-p_{b}\right)}
$$

In which

$$
\begin{gathered}
c=\frac{b}{2\left(a+b p_{b}\right)} \\
{\left[\frac{K_{r o}}{B_{o} \mu_{o}}\right]_{p}=a+b P}
\end{gathered}
$$

Producing gas/oil ratio is the ratio of total gas production volume and total oil production volume at the atmosphere condition, the total gas production volume consist of the gas flowed into wellbore in the form of free gas, and the gas dissolved in the oil in the oilfield which was produced with oil at the same time. According to the fluid mechanics in porous medium theory, the calculation formula of producing gas/oil ratio ${ }^{[8]}$ as follows:

$$
G O R=\frac{K_{r g}}{K_{r o}} \frac{\mu_{o}(p)}{\mu_{g}(p)} B_{o}(p) \frac{p_{R}}{p_{a}}+R_{s}(p)
$$

The formula of average reservoir pressure as follow:

$$
p_{R}=p_{e}-\frac{p_{e}-p_{w f}}{2 \ln \frac{r_{e}}{r_{w}}}
$$

The second factor is seriously smaller than the first one in above formula, so it can be accounted that the boundary pressure $p_{e}$ is similar equaling to average reservoir pressure $p_{R}$, then set of equation (1) (2) (3), the formula as follow:

$$
G O R=\frac{K_{r g}}{K_{r o}} \frac{\mu_{o}(p)}{\mu_{g}(p)} B_{o}(p) \frac{\left[p_{b}-p_{w f}-c\left(p_{b}-p_{w f}\right)^{2}\right] \frac{\ln \frac{d / 2}{r_{b}}}{\ln \frac{r_{b}}{r_{w}}}+p_{b}}{p_{a}}+R_{s}(p)
$$

Above equation is the equation of producing gas/oil ratio and well spacing density, flowing bottom hole pressure, saturation pressure. In it, $d$ is well spacing, $p_{w f}$ is flowing bottom hole pressure, $p_{b}$ is saturation pressure.

\section{The numerical simulation study}

\section{1 construct the basic model of numerical simulation}

Model scale: $2 \mathrm{~m} \times 2 \mathrm{~m} \times 3 \mathrm{~m}$

Grid number: $91 \times 91 \times 1$

One layer, homogeneous layer, permeability is $500 \times$ 10-3 um2, one injection well and one production well, well spacing is $250 \mathrm{~m}$, thickness is $3 \mathrm{~m}$, average porosity 
of the model is 0.2534 , original reservoir pressure is $12 \mathrm{MPa}$, saturation pressure of oil layer is $9.5 \mathrm{MPa}$, flowing bottom hole pressure was set as 3.5 MPa. Construct the black oil model of oil, gas, water phases which include dissolved gas and no volatile oil.

The well location map of basic ideal model as the Figure 3-1.

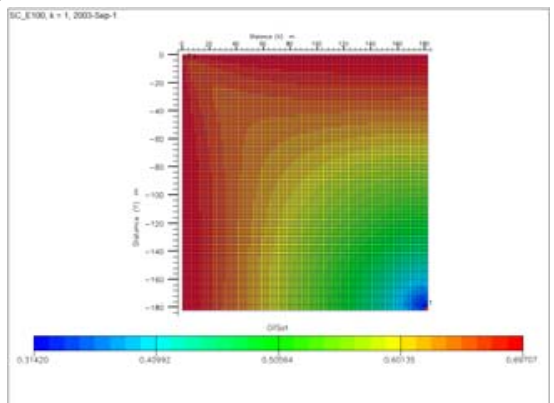

Figure 3-1 Schematic diagram of ideal model based wells

\subsection{The study of the impacts of the change of well spacing density on producing gas/oil ratio.}

\subsubsection{Scheme design}

The following eight groups of experimental program was designed to investigate the impact of the change of well spacing density on the producing gas/oil ratio by the means of changing the grid number of basic model.

Table 3-1 Scheme design table of influence of the density of the well network on the production of gas / oil ratio

\begin{tabular}{c|c|c|c|c}
\hline $\begin{array}{c}\text { Program } \\
\text { sequence }\end{array}$ & $\begin{array}{c}\text { Grid } \\
\text { number }\end{array}$ & $\begin{array}{c}\text { Oil well } \\
\text { coordina- } \\
\text { te }\end{array}$ & $\begin{array}{c}\text { Water well } \\
\text { coordinat-e }\end{array}$ & $\begin{array}{c}\text { Injector } \\
\text { producer } \\
\text { distance/m }\end{array}$ \\
\hline 1 & $47 \times 47 \times 1$ & $(2,2)$ & $(46,46)$ & 125 \\
\hline 2 & $56 \times 56 \times 1$ & $(2,2)$ & $(55,55)$ & 150 \\
\hline 3 & $65 \times 65 \times 1$ & $(2,2)$ & $(64,64)$ & 175 \\
\hline 4 & $74 \times 74 \times 1$ & $(2,2)$ & $(73,73)$ & 200 \\
\hline 5 & $83 \times 83 \times 1$ & $(2,2)$ & $(82,82)$ & 225 \\
\hline 6 & $91 \times 91 \times 1$ & $(2,2)$ & $(90,90)$ & 250 \\
\hline 7 & $100 \times 100 \times 1$ & $(2,2)$ & $(99,99)$ & 275 \\
\hline 8 & $109 \times 109 \times 1$ & $(2,2)$ & $(108$, & 300 \\
\hline
\end{tabular}

In the producing process, the flowing pressure of producing well was set as a constant of $3.5 \mathrm{MPa}$, the injection rate of injection well was set as a constant of $118 \mathrm{~m}^{3} / \mathrm{d}$.

\subsubsection{Result analysis}

According to the production data, the correlation between the producing gas/oil ratio and water cut at the different well spacing was depicted as following Figure 3-2.

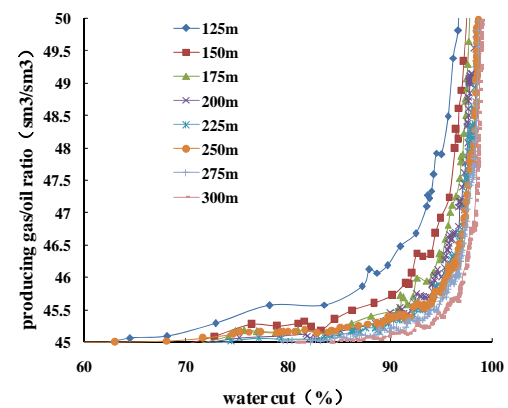

Figure 3-2 Correlation curves of the producing gas/oil ratio and water cut at the different well spacing

According to the production data, the change of gas/oil ratio at the different well spacing and the water cut are ranging from $90 \%$ to $98 \%$ was depicted as following Figure 3-3.

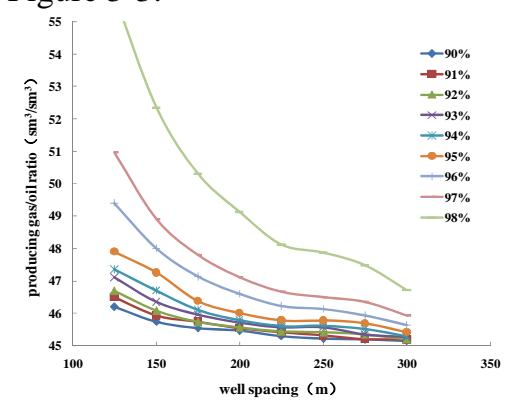

Figure 3-3 Correlation curves of the producing gas/oil ratio and producer injector spacing at the different water cut

According to the above Figure 3-2 and Figure 3-3, the following conclusions are:

1 , Figure 3-2 is the correlation curve which depicted the changing producing gas/oil ratio with the change of water cut at the condition of different well spacing. It can be seen from the figure that, when the bottom hole flowing pressure is a constant, there is a certain amount of influence of water cut on producing gas/oil ratio, the producing gas/oil ratio is ascending with the water cut ascended. The producing gas/oil ratio is 45.72612 $\mathrm{sm} 3 / \mathrm{sm} 3$ when the well spacing is $150 \mathrm{~m}$ and the water cut is $90 \%$, the producing gas/oil ratio is up to 52.36147 $\mathrm{sm} 3 / \mathrm{sm} 3$ when the water cut is up to $98 \%$.

2, Figure 3-3 is the correlation curve which depicted the changing producing gas/oil ratio with the change of well spacing while the water cut are ranging from $90 \%$ to $98 \%$, it is apparent that the producing gas/oil ratio is ascending with the well spacing descended when the water cut is a constant and the other factors remain stationary. The producing gas/oil ratio is 50.96127 $\mathrm{sm} 3 / \mathrm{sm} 3$ when the water cut is $97 \%$ and the well spacing is $125 \mathrm{~m}$, it down to $45.92333 \mathrm{sm} 3 / \mathrm{sm} 3$ when the well spacing is $300 \mathrm{~m}$.

\subsection{The impacts of the change of bottom hole flowing pressure on producing gas/oil ratio.}

\subsubsection{Scheme design}

To observe the change of producing gas/oil ratio in simulated domain, ten groups of experiment projects as 
follows, which are based on the basic model was designed by changing bottom hole flowing pressure and keeping the other parameters unchanged.

Table 3-2 Scheme design table of influence of the density of the well network on the producing gas / oil ratio

\begin{tabular}{|c|c|c|c|}
\hline $\begin{array}{l}\text { Program } \\
\text { sequence }\end{array}$ & $\begin{array}{c}\text { Well } \\
\text { spacing(m) }\end{array}$ & $\begin{array}{c}\text { Saturation } \\
\text { pressure(MPa) }\end{array}$ & $\begin{array}{c}\text { Bottom hole } \\
\text { flowing } \\
\text { pressure(MPa) }\end{array}$ \\
\hline 1 & 250 & 9.5 & 1.0 \\
\hline 2 & 250 & 9.5 & 1.5 \\
\hline 3 & 250 & 9.5 & 2.0 \\
\hline 4 & 250 & 9.5 & 2.5 \\
\hline 5 & 250 & 9.5 & 3.0 \\
\hline 6 & 250 & 9.5 & 3.5 \\
\hline 7 & 250 & 9.5 & 4.0 \\
\hline 8 & 250 & 9.5 & 4.5 \\
\hline 9 & 250 & 9.5 & 5.0 \\
\hline 10 & 250 & 9.5 & 5.5 \\
\hline
\end{tabular}

The flow pressure of producing well which was set as a constant in producing process are the above flow pressure in those groups, the injection rate was set as constant of $90 \mathrm{~m}^{3} / \mathrm{d}$.

\subsubsection{Result analysis}

According to the production data, the correlation between the producing gas/oil ratio and water cut at the different bottom hole flowing pressure was depicted as following Figure 3-4.

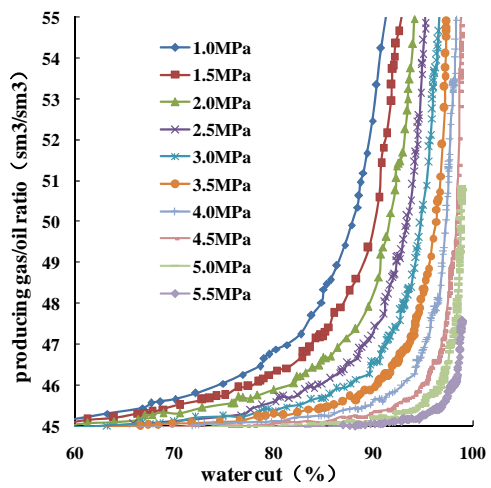

Figure 3-4 Correlation curves of the producing gas/oil ratio and water cut at the different bottom hole flowing pressure

The correlation curve which depicts the producing gas/oil ratio and the bottom hole flowing pressure at the different water cut as following Figure 3-5.

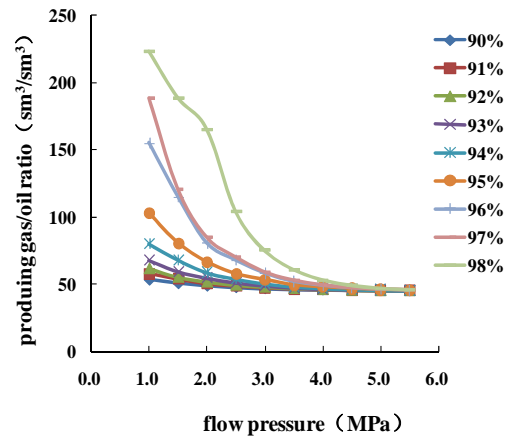

Figure 3-5 Correlation curves of the producing gas/oil ratio and bottom hole flowing pressure at the different water cut

According to the above Figure 3-4 and Figure 3-5, the following conclusions are:

1 , Figure 3-4 is the correlation curve which depicted the changing producing gas/oil ratio with the change of water cut at the condition of different bottom hole flowing pressure. It can be seen from the figure that, when the bottom hole flowing pressure is a constant, there is a certain amount of influence of water cut on producing gas/oil ratio, the producing gas/oil ratio is ascending with the water cut ascended. The producing gas/oil ratio is $67.40336 \mathrm{sm} 3 / \mathrm{sm} 3$ when the bottom hole flowing pressure is $1.0 \mathrm{MPa}$ and the water cut is $93 \%$, the producing gas/oil ratio is up to $223.0594 \mathrm{sm} 3 / \mathrm{sm} 3$ when the water cut is up to $98 \%$.

2, Figure 3-5 is the correlation curve which depicted the changing producing gas/oil ratio with the change of bottom hole flowing pressure while the water cut are ranging from $90 \%$ to $98 \%$, it is apparent that the producing gas/oil ratio is ascending with the bottom hole flowing pressure descended when the water cut is a constant and the other factors remain stationary. The producing gas/oil ratio is $67.40336 \mathrm{sm} 3 / \mathrm{sm} 3$ when the water cut is $93 \%$ and the bottom hole flowing pressure is $1.0 \mathrm{MPa}$, it down to $45.18897 \mathrm{sm} 3 / \mathrm{sm} 3$ when the bottom hole flowing pressure is $5.5 \mathrm{MPa}$.

\subsection{The impacts of the change of bottom hole flowing pressure on producing gas/oil ratio.}

\subsubsection{Scheme design}

To observe the change of producing gas/oil ratio in simulated domain, eight groups of experiment projects as follows, which is based on the basic model was designed by changing the saturation pressure and keeping the other parameters unchanged. 
Table 3-3 Scheme design table of influence of the saturation pressure on the producing gas / oil ratio

\begin{tabular}{|c|c|c|c|}
\hline $\begin{array}{c}\text { Program } \\
\text { sequence }\end{array}$ & $\begin{array}{c}\text { Well } \\
\text { spacing(m) }\end{array}$ & $\begin{array}{c}\text { Bottom hole } \\
\text { flowing } \\
\text { pressure(MPa) }\end{array}$ & $\begin{array}{c}\text { Saturation } \\
\text { pressure(MPa) }\end{array}$ \\
\hline 1 & 250 & 3.5 & 7.5 \\
\hline 2 & 250 & 3.5 & 8.0 \\
\hline 3 & 250 & 3.5 & 8.5 \\
\hline 4 & 250 & 3.5 & 9.0 \\
\hline 5 & 250 & 3.5 & 9.5 \\
\hline 6 & 250 & 3.5 & 10.0 \\
\hline 7 & 250 & 3.5 & 10.5 \\
\hline 8 & 250 & 3.5 & 11.0 \\
\hline
\end{tabular}

The flow pressure of producing well was set as a constant of $3.5 \mathrm{MPa}$ in producing process, the injection rate was set as constant of $90 \mathrm{~m}^{3} / \mathrm{d}$.

\subsubsection{Result analysis}

According to the production data, the correlation between the producing gas/oil ratio and water cut at the different saturation pressure was depicted as following Figure 3-6.

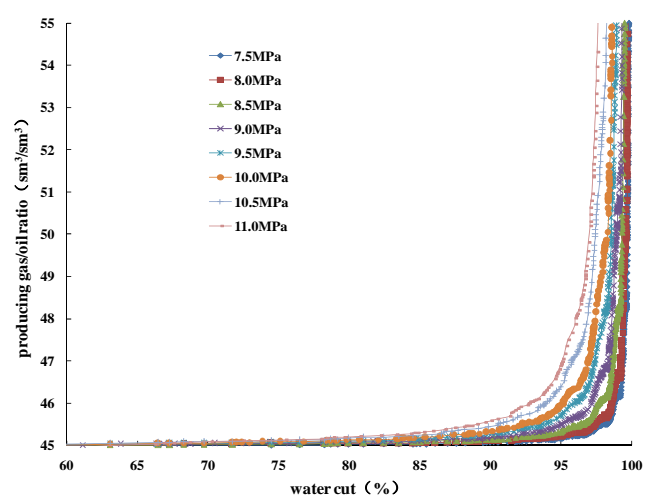

Figure 3-6 Correlation curves of the producing gas/oil ratio and water cut at the different saturation pressure

The correlation curve which depicts the producing gas/oil ratio and the saturation pressure at the different water cut as following Figure 3-7.

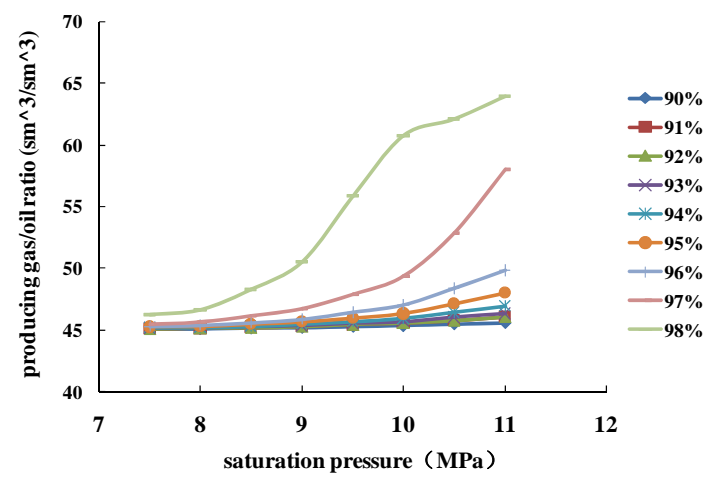

Figure 3-7 Correlation curves of the producing gas/oil ratio and saturation pressure at the different water cut

According to the above Figure 3-6 and Figure 3-7, the following conclusions are:
1, Figure 3-6 is the correlation curve which depicted the changing producing gas/oil ratio with the change of water cut at the condition of different saturation pressure. It can be seen from the figure that, when the saturation pressure is a constant, there is a certain amount of influence of water cut on producing gas/oil ratio, the producing gas/oil ratio is ascending with the water cut ascended. The producing gas/oil ratio is 47.08702 $\mathrm{sm} 3 / \mathrm{sm} 3$ when the saturation pressure is $10.0 \mathrm{MPa}$ and the water cut is $90 \%$, the producing gas/oil ratio is up to $60.76317 \mathrm{sm} 3 / \mathrm{sm} 3$ when the water cut is up to $98 \%$.

2, Figure 3-7 is the correlation curve which depicted the changing producing gas/oil ratio with the change of saturation pressure while the water cut are ranging from $90 \%$ to $98 \%$, it is apparent that the producing gas/oil ratio is ascending with the saturation pressure ascended when the water cut is a constant and the other factors remain stationary. The producing gas/oil ratio is 45.49727 $\mathrm{sm} 3 / \mathrm{sm} 3$ when the water cut is $97 \%$ and the saturation pressure is $7.5 \mathrm{MPa}$, it up to $57.98391 \mathrm{sm} 3 / \mathrm{sm} 3$ when the bottom hole flowing pressure is $10.0 \mathrm{MPa}$.

\section{Conclusion}

(1) When the well spacing is a constant, there is a certain amount of influence of water cut on producing gas/oil ratio, the producing gas/oil ratio is ascending with the water cut ascended. The producing gas/oil ratio is ascending with the well spacing ascended when the water cut is a constant and the other factors remain stationary.

(2) When the bottom hole flowing pressure is a constant, there is a certain amount of influence of water cut on producing gas/oil ratio, the producing gas/oil ratio is ascending with the water cut ascended. The producing gas/oil ratio is ascending with bottom hole flowing pressure ascended when the water cut is a constant and the other factors remain stationary.

(3) When the saturation pressure is a constant, there is a certain amount of influence of water cut on producing gas/oil ratio, the producing gas/oil ratio is ascending with the water cut ascended. The producing gas/oil ratio is ascending with the saturation pressure ascended when the water cut is a constant and the other factors remain stationary.

\section{References}

[1] D.W. Huang, J.L. Wang, Y.B. Qu, Z.P. Li, P. Guo, Y.J. Chen. Experimental Study on Various Gas mil Ratio Fluid Properties and Petrophysical Parameters [J] Logg. Tech. 34(5), 411-414 (2010)

[2] Y.S. Zhao, S.Y. Zhang, N. Zhu. Production GOR variation of La, Sa, Xing oilfield [J] Daq. Petr. Geol. and Deve. 17 (1),22-25(1998)

[3] Y.B Lan. A Study of Gas/oil Ratio in Gas Cap Oil Field on Lamadian [M]. Daq. Petr. Inst. 68-69(2003)

[4] D. Jacqmin. Interaction of natural convection and gravity segregation in oil/gas reservoirs[C]//paper 16703-MS presented at the Annual Technical Conference and Exhibition, 27-30 September 1987, Dallas, USA. Ncw York: SPE 1987. 
[5] Q. Zhang, H.F. Yu, Y. Bai, Y. Jiang, L.M. Huang, J. Han. Variation of Gas-Oil Ratio in East Test Area in Tazhong No.l Gas Field, Tarim Basin [J] Xinj. Petro. Geol. 32 (3), 285- 287(2011)

[6] J.D. Zheng, Y.Q. Zhang, G.D. Li, H. Wu. Change of sazhong region's oil bubble point pressure in the process of flooding [J]. Jour. of daqi. Petr. Inst. 21 (4), 22-25 (1997)

[7] X.D. Tian, B.Y. Ji, X.H. Wu. Degassing Radius, formation pressure distribution and average formation pressure after oil well degassed [J]. Jour. of daqi. petr. Geol. and deve. 46-48(1997)

[8] Y.F. Zhai. Percolation mechanics [M]. Beij. petr. industry press,( 2009.7) 